\title{
Alcances y límites de perspectivas psicoanalíticas en historia
}

\author{
MARÍA InÉs MudROVCIC \\ Centro de Investigaciones en Filosofía \\ de las Ciencias Sociales y Humanidades \\ Universidad Nacional del Comahue \\ mmudrovc@neuquen.com.ar
}

\begin{abstract}
Resumen: Algunas vertientes de la historiografía contemporánea han utilizado la categoría de trauma para ilustrar la naturaleza indecidible tanto de nuestras experiencias históricas de catástrofes colectivas como de nuestras representaciones de las mismas. Por desgracia, el uso de las versiones psicoanalíticas y neurológicas del concepto de trauma no da cuenta de la dinámica social de la memoria colectiva, dado que dicha categoría fue acuñada como un concepto referido a la memoria individual de las personas. En este trabajo me centraré en uno de los problemas involucrados: el problema ontológico. Argumentaré que la temporalidad del trauma es incompatible con la temporalidad de la historia.
\end{abstract}

Palabras clave: trauma, historiografía, temporalidad, memoria colectiva

La transposición de categorías patológicas al plano de lo histórico puede ser interpretada como una tentativa de dar sentido a la relación fundamental de la historia con la violencia, relación que Hobbes transformó en origen del pacto contractual. Los regímenes totalitarios latinoamericanos, el Apartheid, el Holocausto o Hiroshima constituyen algunos de los acontecimientos del siglo xx que enfrentaron al historiador con el problema de representar lo que Hannah Arendt ha denominado "la banalidad del mal". La posibilidad de una reconstrucción realista de acontecimientos límite por medio de los procedimientos estándar de la historiografía ha sido puesta en duda desde dentro mismo de la profesión histórica. Parafraseando a Adorno, ${ }^{1}$ eminente historiador del Holocausto, Raul Hilberg se pregunta: "Yo no soy un poeta [...], pero, ¿no es igualmente bárbaro escribir notas a pie de página después de Auschwitz?", y más adelante agrega: "algunas personas que lean lo que he escrito tendrán la creencia errada de que aquí, en mis páginas impresas, encontrarán la verdad última del Holocausto tal como realmente ocurrió". ${ }^{2}$

En un punto extremo se encuentran aquellos que invalidan cualquier aproximación cognitiva fundándose en la "singularidad" de dichos acontecimientos. Esta tendencia cuestiona la posibilidad de que el Holocausto,

${ }^{1}$ T. Adorno, Prisms, p. 84.

${ }^{2}$ R. Hilberg, "I Was Not There", p. 25. 
por ejemplo, sea abordado por las técnicas tradicionales del conocimiento histórico, transformándolo en objeto de lo sublime y, en cuanto tal, en incognoscible e indecible: "Auschwitz no puede ser explicado ni visualizado [...], el Holocausto trasciende la historia." 3 En este contexto, un número cada vez mayor de historiadores se inclina a pensar que las insuficiencias conceptuales y metodológicas de la historiografía para abordar este tipo de acontecimientos se deben a que no dan cuenta de lo que estos acontecimientos manifiestamente son: experiencias traumáticas de las sociedades contemporáneas. Conceptualizar un evento histórico como trauma autorizaría, entonces, a adoptar categorías psicoanalíticas en los análisis históricos.

Esta introducción de la psicología en la historia no es nueva. En 1950, en Estados Unidos, se acuña el término de psicohistoria para designar la nueva perspectiva psicológica en los estudios históricos. W. Langer, presidente de la American Historical Association, legitima el uso del psicoanálisis y sorprende a sus colegas al afirmar que la "nueva tarea" de la historia consiste en "tomar más en serio a la psicología". ${ }^{4}$ Aun cuando la nueva tendencia propició la aparición de numerosas psicobiografías de grandes personalidades durante los años sesenta y setenta, los historiadores se mostraron generalmente reacios a aplicar métodos psicológicos en las reconstrucciones del pasado. En los años treinta, los líderes de Annales, M. Bloch y L. Febvre, habían comenzado a practicar lo que ellos denominaron "psicología histórica", un intento de privilegiar la psicología colectiva por sobre la individual para el análisis de grupos y culturas históricas. A pesar de ello, el programa no se mantuvo durante mucho tiempo, pues, al nacer la "historia de mentalidades", se efectuó un giro hacia la antropología.

Sin embargo, este proyecto que, a juicio de Peter Burke, ${ }^{5}$ se encuentra "casi abandonado" ha sufrido un nuevo impulso durante la última década dentro del género historiográfico denominado "historia del presente" o "historia del pasado reciente". En efecto, la historia del presente, entendida como aquella historiografía que intenta reconstruir acontecimientos que constituyen recuerdos de, al menos, una de las generaciones vivas, ${ }^{6}$ ha centrado su atención en acontecimientos trágicos de la historia reciente. En este contexto y tal como se señalara anteriormente, el concepto de "trauma" ha ocupado un lugar central en la caracterización de los fenómenos estudiados $^{7}$ y a partir de allí muchos historiadores han privilegiado una aproximación psicoanalítica a los mismos. Subyace como presupuesto de

${ }^{3}$ E. Wiesel, Against Silence: The Voice and Vision of Elie Wiesel, ed. Irving Abrahamson, Holocaust Library, Nueva York, 1985, p. 158.

${ }^{4}$ W. Langer, "The New Assignment", pp. 283-304.

${ }^{5}$ P. Burke, History and Social Theory, p. 115.

${ }^{6}$ M.I. Mudrovcic, "Algunas consideraciones epistemológicas para una 'Historia del presente"".

${ }^{7}$ D. LaCapra, Writing History, Writing Trauma (2001); C. Caruth, Unclaimed Experience: 
esta tendencia teórica la convicción de un vínculo estrecho entre historia y memoria. Dicho vínculo se encuentra reflejado no sólo en el proceso de la comprensión histórica del pasado reciente, sino en el reconocimiento de que la investigación crítica contribuye a la constitución de una esfera pública, cognitivamente responsable.

En sus orígenes, la palabra trauma se aplicó a los síntomas producidos por una lesión orgánica. La concepción moderna de trauma se originó en el trabajo del médico inglés John Erichsen, quien, en 1860, identificó el "síndrome del trauma" en víctimas que sufrían de terror a los accidentes de ferrocarril, y los atribuyó a una contusión de la espinal dorsal. Sin embargo, el término "trauma" recibió un sentido psicológico cuando fue empleado por J.M. Charcot, P. Janet, A. Binet, J. Breuer y S. Freud para describir una lesión ("herida") de la mente causada por un shock emocional súbito e inesperado. Recientemente, en 1980, un modelo de trauma se institucionaliza en el concepto de estrés postraumático (PTSD) a través del reconocimiento oficial de la American Psychiatric Association. El estrés postraumático es fundamentalmente un desorden de la memoria. Debido a las fuertes emociones de terror y sorpresa causados por ciertos eventos, la mente se disocia: es incapaz de registrar la herida de la psique porque los mecanismos ordinarios de conciencia y cognición son destruidos. ${ }^{8}$

Dentro de la vasta bibliografía dedicada al tema de la relación del trauma con la historia, quiero distinguir, en primer lugar, dos tipos de aproximaciones diferentes: una que podemos denominar especulativa y otra que llamaremos empírica. Denomino aproximación especulativa de la historia como trauma al modelo teórico que entiende el desarrollo de los procesos históricos - historia como res gestae- como el retorno de lo que ha sido históricamente reprimido. La noción de trauma se constituye en clave para interpretar el sentido de la historia, al igual que la lucha de clases lo fue para Marx, o el desarrollo del espíritu para Hegel. Los argumentos se sostienen a partir de ciertas obras de Freud que, como "Psicología colectiva y análisis del yo" (1921), Moisés y el monoteísmo (1939) o Tótem y tabú (1912-1913), invalidan la ruptura entre psicología individual y psicología colectiva. Con relación a este último libro, Freud afirma en 1914: "intento aplicar el método analítico a problemas que, relacionados con la psicología de los pueblos, nos hacen remontarnos a los orígenes de las instituciones más importantes de nuestra civilización: organización

Trauma, Narrative and History (1996); E. Wartes, Memory Quest: Trauma and the Search for Personal History (1997); L. Gilmore, The Limits of Autobiography: Trauma and Testimony (2001); A. Neal, National Trauma and Collective Memory: Major Events in the American Century (1998); N. Popov, The Road to War in Serbia. Trauma and Catharsis (1999); Dan Bar-On, The Indescribable and Undiscussible. Reconstructing Human Discourse After Trauma (1999), etcétera.

${ }^{8}$ Cfr., al respecto, R. Leys, Trauma. A Genealogy, pp. 2-4. 
política, moral, religión, pero también a la prohibición del incesto y al remordimiento". 9 Sin embargo, aun cuando el mismo Freud planteó dudas acerca del estatus de sus investigaciones sociohistóricas, historiadores como Caruth o Langmuir, ${ }^{10}$ por ejemplo, extienden su aparato analítico a fenómenos colectivos. El proceso de secularización occidental se interpreta, entonces, como un proceso que involucró un conflicto entre las fuerzas emergentes - tales como la ciencia, los modos "racionales" de producción económica, las conductas burocráticas, etc.- y las prácticas y creencias religiosas primitivas. Dado que la ruptura con este mundo simbólico fue traumática, "habría una propensión de lo reprimido a retornar bajo formas distorsionadas, particularmente en un movimiento como el nazismo, que [...] proclama simultáneamente su ímpetu neopagano y su inserción en el popular antisemitismo cristiano". ${ }^{11}$ El trauma se transforma, entonces, en condición de posibilidad de la historia.

A la caracterización anterior de la historia como trauma podemos oponer una aproximación empírica del trauma en la historia. En los análisis históricos de esta naturaleza, el concepto de trauma constituye una categoría de análisis de valor heurístico a la hora de dar cuenta de los fenómenos históricos concretos de nuestro pasado reciente. Desde este ángulo, los fenómenos sociales contemporáneos son categorizados como traumáticos, lo que autorizaría la importación de perspectivas teóricas y técnicas psicoanalíticas al campo de la historiografía. Los problemas filosóficos y epistemológicos involucrados son numerosos: desde la cuestión más general de la atribución de predicados individuales a sujetos colectivos, hasta la más específica de la historia como crítica sociopolítica. En el presente trabajo me centraré en el problema de la temporalidad e intentaré argumentar que la temporalidad del trauma es incompatible con la temporalidad histórica. En otras palabras, si aceptamos la condición de traumatizadas de las sociedades contemporáneas como consecuencia de los acontecimientos extremos experimentados en el siglo Xx, esto mismo hace imposible escribir su historia. Donde hay trauma, no hay historia.

El trabajo se articulará en torno a tres cuestiones que podemos encontrar sintetizadas en los siguientes párrafos:

1) Una cuestión historiográfica expresada del siguiente modo por LaCapra: "Se puede observar que la Shoa es un caso extremo de una serie traumática de eventos que coloca (al historiador) frente a los problemas de la negación o el rechazo, la repetición y la elaboración." 12

${ }^{9}$ S. Freud, "Contribution a l'histoire du mouvement psychanalytique", p. 113.

${ }^{10}$ G. Langmuir, History, Religion, and Antisemitism; C. Caruth, Unclaimed Experience. Trauma, Narrative, and History.

${ }^{11}$ D. LaCapra, Representing the Holocaust. History, Theory, Trauma, pp. 170-171.

12 Ibid, p. 188. 
2) Una cuestión psicológica resumida en una cita de Caruth: "El trauma describe la experiencia de sucesos catastróficos y la respuesta a dicha experiencia a través de fenómenos repetitivos." ${ }^{13}$

3) Una cuestión epistemológica sintetizada en un párrafo de Certeau: "La historiografía se desarrolla [...] en función de una ruptura entre el pasado y el presente [...]. Una frontera separa la institución actual (que fabrica representaciones) de las antiguas o lejanas (que las representaciones historiográficas ponen en escena)."14

Central para el estudio de la memoria tal como es entendida por el psicoanálisis es la distinción entre dos formas de traer el pasado al presente: la repetición y el recuerdo. La repetición consiste en un tipo de acción en la cual el sujeto, apresado por fantasías y deseos inconscientes, ${ }^{15}$ los pone de relieve en el presente con una impresión de inmediación que es resaltada por el rechazo o incapacidad del analizado de reconocer su origen y, por lo tanto, su carácter repetitivo. La conducta de repetición generalmente despliega un aspecto compulsivo y a menudo toma la forma de una conducta agresiva que puede ser dirigida hacia otros o hacia el propio sujeto. Desde el punto de vista explicativo, la cuestión central es la compulsión a repetir. Como resultado de esta compulsión a repetir, el paciente se coloca deliberadamente en una situación de angustia: repite la situación original de trauma. Sin embargo, en la repetición compulsiva el sujeto no recuerda el prototipo de sus acciones presentes (la mujer se une a parejas golpeadoras, repitiendo, sin saberlo, la experiencia traumática de un padre golpeador, por ejemplo). Por el contrario, el sujeto tiene la fuerte impresión de que la situación en la que se encuentra "atrapado" está enteramente determinada por las circunstancias presentes. El recuerdo reprimido está activo en el presente: el paciente, dice Freud, no recuerda nada de lo olvidado, sino que lo actúa. ${ }^{16}$ La compulsión a repetir ha reemplazado a la capacidad de recordar. El sujeto repite en vez de recordar y repite en condiciones de resistencia. Esta teoría, central para la técnica analítica, aparece en un texto que Freud escribió en 1914: "Recordar, repetir y elaborar".

La noción de repetición se conserva, asimismo, en el diagnóstico del desorden del estrés postraumático que fue codificado en 1980 en la tercera

${ }^{13}$ C. Caruth, op. cit., p. 11.

${ }^{14}$ M. de Certau, Historia y psicoanálisis, p. 78.

${ }^{15}$ En 1890, Freud sugiere que la repetición era causada por memorias reprimidas de un trauma sexual. En 1897 abandona la teoría de la seducción y reorienta su trabajo hacia el estudio de los efectos de la represión de las fantasías eróticas infantiles. Sin embargo, en "Más allá del principio del placer" (1920), Freud reconoció la existencia de una tendencia a la muerte que actuaría en oposición al principio del placer.

${ }^{16}$ S. Freud, "Recordar, repetir y elaborar", p. 152. 
edición del Diagnostic and Statistical Manual of Mental Disorders. Los sueños traumáticos, los flashbacks y otras experiencias intrusivas son considerados recuerdos literales del evento traumático. Para el médico B. van der Kolk, figura central en el estudio científico del trauma, el evento traumático se codifica en el cerebro de una manera diferente de como se codifica la memoria ordinaria. La memoria traumática es literal en el sentido de que no está integrada en la conciencia, sino disociada de la misma y, por lo tanto, es imposible recuperarla por el recuerdo ordinario. ${ }^{17}$ Por lo anterior, la memoria traumática en su repetición no está sujeta a los procesos usuales de integración. En consecuencia, desde esta perspectiva, la repetición es la reiteración literal y no la represión del evento traumático.

Ambos modelos de repetición, la memoria literal y la memoria represiva, han servido como conceptos clave para la interpretación de la historia del pasado reciente. LaCapra, por ejemplo, se sirve del modelo represivo, mientras que Caruth se apoya en la interpretación de la memoria traumática como literal.

Con relación a esta cuestión, Freud, en el ensayo de 1914, introduce el tópico de la transferencia: un fenómeno que él discute en términos de la relación entre el analista y el analizado, porque, aunque la transferencia no esté confinada sólo a esta relación, la conducta de la repetición es observable directamente dentro del espacio analítico. Freud describe la transferencia como el instrumento principal para "contrarrestar la compulsión del paciente a repetir y transformarlo en un motivo para el recuerdo". ¿Por qué la transferencia tiene este efecto? Si el recuerdo aparece, dice Freud, es porque la transferencia constituye algo así como "la palestra" en la que se permite que la compulsión a repetir del paciente se manifieste en forma libre. La transferencia constituye un "medio entre la enfermedad y la vida real a través del cual se realiza la transición de una a otra". Este medio consiste, en gran medida, en una actividad narrativa: el analizado habla de su pasado, de su vida presente fuera del análisis, de su vida dentro del análisis. Freud nunca discutió explícitamente el carácter narrativo de la experiencia psicoanalítica, pero autores posteriores como Janet, Sherwood y Spencer ${ }^{18}$ han señalado su carácter central y han mostrado las formas en las que el diálogo psicoanalítico busca sortear los esfuerzos del analizado por mantener una especie de discontinuidad narrativa. El punto central de esta discontinuidad narrativa es bloquear partes del pasado personal y, al hacerlo, bloquear también los orígenes significantes de las acciones presentes. Para tratar de eliminar esta discontinuidad radical, el psicoanálisis trabaja en un

\footnotetext{
${ }^{17}$ B. van der Kolk, A. McFarlane y L. Weisath, Traumatic Stress: The Effects of Overwhelming Experience on Mind, Body, and Society; B. van der Kolk, "The Body Keeps the Score: Memory and the Evolving Psychobiology of Post Traumatic Stress".

${ }^{18}$ M. Sherwood, The Logic of Explanation in Psychoanalysis; D. Spence, Historical Truth and Narrative Truth: Meaning and Interpretation un Psychoanalisis.
} 
círculo temporal: el analista y el analizado trabajan "hacia atrás" cuando se habla del presente autobiográfico para reconstruir un relato coherente del pasado, y, al mismo tiempo, trabajan "hacia delante" a partir del pasado autobiográfico para reconstruir ese relato del presente que se busca entender y explicar. Hay una regla en los escritos técnicos de Freud que advierte que el analista debe dirigir su atención al pasado cuando el analizado insiste en hablar del presente, y buscar en el presente cuando el analizado se remite al pasado. Ambos conjuntos de relatos deben generar cuestiones que permitan relacionarlos. Recordar, entonces, no es rememorar eventos aislados, sino ser capaz de formar una secuencia narrativa significativa de los mismos. Se intenta, entonces, integrar fenómenos aislados o extraños en un relato unificado. Es éste el sentido en que el psicoanálisis se arroga la tarea de reconstituir las historias de vidas individuales. Ahora bien, para los fines de este trabajo, es importante subrayar, que, en la medida en que la experiencia analítica intenta estructurar narrativamente una vida, sus criterios no son los de la verificación. El analista no está interesado en los hechos, sino en la capacidad de hacer un todo significativo de la historia de nuestra vida, que intenta salvar la brecha entre la memoria traumática y la memoria narrativa. La tarea del psicoterapeuta, entonces, es lograr que el paciente pueda disolver su amnesia contando la historia del evento traumático. En definitiva, que pueda decir: "yo recuerdo". Para Janet, la memoria es la capacidad que tiene la persona de poder distanciarse de sí misma, para que pueda, entonces, representar sus experiencias, tanto a sí misma como a los otros, en forma de una historia narrada. En un escrito de 1919, Janet afirma:

La memoria, como la creencia, como cualquier otro fenómeno psicológico, es una acción; esencialmente, es la acción de contar una historia [...]. El narrador no sólo debe saber cómo narrar el evento, sino también debe saber cómo asociarlo con otros eventos de su vida [...]. Estrictamente hablando, aquel que posea una idea fija de un suceso no puede decirse que posea una "memoria" del mismo. Es sólo por conveniencia que hablamos, en este caso, de "memoria traumática". El sujeto es incapaz de transformar el suceso en el relato que nosotros llamamos memoria. ${ }^{19}$

Quisiera establecer, en este punto, una analogía entre estas dos formas de la memoria individual que distingue Freud - la repetición y el recuerdo- con lo que Todorov denomina memoria literal y memoria ejemplar de los pueblos. Todorov realiza esta distinción en el marco de su crítica acerca de los usos de la memoria. Un acontecimiento doloroso del pasado de un grupo "se conserva en su literalidad (lo que no significa su verdad)

${ }^{19}$ P. Janet, Psychological Healing. A Historical and Clinical Study (1919). 
cuando permanece intransitivo y no conduce más allá de sí mismo". ${ }^{20} \mathrm{Se}$ establece, entonces, una relación de contigüidad entre ese pasado y el presente del grupo, extendiendo las consecuencias del trauma inicial a todos los instantes de la existencia. La otra forma del recuerdo, la ejemplar, se caracteriza por recuperar el carácter pasado del acontecimiento y, sin abandonar su singularidad, lo transforma en modelo para actuar en el presente frente a situaciones nuevas. El recuerdo se convierte en exemplum y, por lo mismo, en "principio de acción" para el presente. Por el contrario, la memoria literal transforma en insuperable el acontecimiento, sometiendo el presente al pasado, dominado éste por el recuerdo, sin poder controlarlo. Esto sucede en los grupos atrapados en una conmemoración obsesiva del acontecimiento, en un "frenesí de liturgias históricas". Al llamamiento retórico del "deber guardar memoria", Todorov responde con una pregunta: ¿para qué? La preocupación por la rememoración compulsiva de la tragedia esconde la apelación a la unicidad e incomparabilidad del acontecimiento, y al sustraerlo del debate racional, lo convierte en inefable. Si Auschwitz, Kolyma o Hiroshima se caracterizan por su "singularidad única", mal pueden servirnos de claves para entender el presente. La memoria literal, la repetición ritual conmemorativa debe ser transformada en memoria ejemplar para que el recuerdo del horror pasado mantenga alerta al grupo frente a situaciones nuevas y, sin embargo, análogas.

Ahora bien, si aceptamos con Todorov estas dos formas de reminiscencia social, la literal y la ejemplar, la pregunta que se nos ocurre es: ¿cómo se pasa de la una a la otra? ¿De qué modo una comunidad, cuyos diferentes grupos han experimentado directa o indirectamente eventos traumáticos, deja de estar atrapada compulsivamente por su pasado y transforma los acontecimientos trágicos de la que es heredera en recuerdos ejemplares que guíen las acciones presentes? En definitiva, ¿cómo se realiza un duelo social? Todorov no nos da ninguna pista al respecto; sin embargo, podemos encontrar la respuesta a estas preguntas en un texto de LaCapra, para quien "la historiografía implica un trabajo sobre la memoria que inquiere en sus operaciones, intenta recuperar lo que ha sido reprimido o ignorado, y lo complementa de modo tal que pueda brindar cierta distancia crítica sobre la experiencia y una base para la acción responsable"; ${ }^{21}$ y en otra parte agrega: "La historiografía puede ayudar a [...] conciliarnos con las heridas y cicatrices del pasado." 22 De este modo, la historia se convierte en una práctica mediadora que proveería la distancia necesaria respecto de los acontecimientos de manera tal que, al restituirles su condición de pasado, contrarrestaría los efectos postraumáticos reconstruyendo la vida individual y social. El historiador se transforma en terapeuta social.

20 T. Todorov, Los abusos de la memoria, p. 30.

${ }^{21}$ D. LaCapra, Representing the Holocaust, p. 175.

${ }^{22}$ D. LaCapra, Writing History, Writing Trauma, p. 42. 
A la cuestión de los problemas de la representación de acontecimientos traumáticos del pasado reciente, autores como Caruth o LaCapra responden con una historiografía de molde psicoanalítico. Para estos historiadores, una perspectiva teórica de esta naturaleza impediría caer en las limitaciones propias del modelo documental o realista, por un lado, o del modelo constructivista radical o antirrealista, por el otro. ${ }^{23} \mathrm{El}$ objetivo del modelo documental o realista de la historia se reduce a formular una narración continua en la que el valor de verdad de las proposiciones se infiere a partir de la evidencia de que se dispone. Para el modelo radical o antirrealista, por el contrario, los acontecimientos no pueden ser capturados a partir de esquemas tradicionales de representación, y el acento debe ser puesto en factores ideológicos, estéticos o retóricos, puesto que el objeto se encuentra más allá de todo conocimiento posible. En el primer caso, las insuficiencias del modelo se traducen en que transforman el discurso histórico en una serie de proposiciones asertóricas que soslayan las implicaciones del historiador en los acontecimientos abordados y, al hacerlo, ignoran los presupuestos y los compromisos afectivos y valorativos que suscita el trauma. En el segundo caso, se imposibilita el discurso histórico al convertir el acontecimiento en incognoscible. La coexistencia de estas dos aproximaciones opuestas constituye, para algunos, no sólo un síntoma que testifica la naturaleza conflictiva de los fenómenos estudiados, sino que, además, da cuenta de la necesidad de una metodología interdisciplinaria para abordarlos. Si la categoría de trauma conviene a los eventos del pasado reciente, una perspectiva psicoanalítica de la historiografía no es sólo plausible, sino deseable. Puesto que la actividad cognitiva de superar resistencias y el reconocimiento son las implicaciones de la situación analítica, esta experiencia es transformada por la historiografía en un modelo estructural. Se califica, entonces, de reduccionista la actitud de confinar el psicoanálisis a una psicología del individuo, y se considera que ciertos conceptos clave, tales como transferencia, rechazo, negación, repetición y elaboración, son cruciales en el intento de elucidar no sólo la relación entre culturas, sino, sobre todo, la relación del presente con el pasado. ${ }^{24}$

La noción de trauma se constituye en la condición de posibilidad de comprender la historicidad de las sociedades contemporáneas herederas de los acontecimientos trágicos del pasado reciente. En este contexto, el uso sociocultural de los conceptos psicoanalíticos no debe ser entendido como analógico, pues se considera que dichos conceptos atraviesan la oposición entre individuo y sociedad en la medida en que los procesos a los que refieren involucran el estatus social del individuo. ${ }^{25} \mathrm{El}$ uso de técnicas

${ }^{23}$ Cfr. M. Rothberg, Traumatic Realism. The Demands of Holocaust Representation, p. 4; D. LaCapra, Writing History, Writing Trauma, p. 1.

${ }^{24}$ D. LaCapra, Representing the Holocaust, p. 9.

${ }^{25}$ Ibid. 
estándar en la autenticación de documentos, las notas a pie de página, la validación empírica de las afirmaciones —utilizados como únicos recursos de la investigación historiográfica- conduce, a juicio de algunos, a una excesiva objetivación y normalización de fenómenos como el Holocausto a través de "narrativas armónicas". ${ }^{26}$ Cierto tipo de empatía, entendido como un componente afectivo difícil de controlar (empathic unsettlement), es necesario para la comprensión histórica de estos fenómenos. Dicha empatía, según LaCapra, está ligada a "una relación transferencial con el pasado, y constituye el aspecto afectivo de la comprensión, el cual pone límites a la objetificación (objectification) e involucra al historiador con el pasado, sus actores y víctimas". ${ }^{27} \mathrm{El}$ concepto de transferencia no es una simple analogía con la situación analítica, sino que esta última se entiende como una versión condensada de un proceso transferencial general que se cumple en todas las relaciones. ${ }^{28}$ Desde esta perspectiva, el recurso a la transferencia es metodológicamente insoslayable a la hora en que el historiador debe enfrentarse con los testimonios de los sobrevivientes. La importancia de los testimonios orales va más allá de la información documental que pudieran ofrecer. El testimonio no es valorado en la medida en que pueda ofrecer un relato de lo que "verdaderamente ocurrió". ${ }^{29}$ Por el contrario, en el intento por comprender empáticamente la experiencia del pasado, el historiador se ve afectivamente implicado en su relación con la víctima, lo que posee consecuencias generales en el resultado de la investigación histórica.

En la memoria traumática del sobreviviente, el acontecimiento experimentado no está sujeto a un recuerdo consciente, sino que se repite compulsivamente en el presente: retorna en pesadillas, flashbacks, ataques de ansiedad y otras formas intrusivas de conductas repetitivas características de una ruptura del horizonte de sentido. De esta forma, el pasado es revivido de modo incontrolado en el presente de manera tal que, al romperse la distancia temporal entre ambos, pasado y presente, se colapsan. El sujeto es atrapado performativamente en la repetición de las escenas traumáticas, escenas en las que el sujeto revive el pasado en el presente y se bloquea cualquier distinción temporal. En síntesis, caemos en la paradoja de que las víctimas de memorias traumatizadas no pueden ser testigos del trauma vivido en el sentido de narrarlo y representarlo cognitivamente a otros y a sí mismos: todo lo que pueden hacer es repetir la experiencia como si estuviese literalmente ocurriendo de nuevo. En palabras del psicoanalista D. Laub: "la sola circunstancia de haber estado dentro del evento [...]

${ }^{26}$ D. LaCapra, Writing History, Writing Trauma, p. 103.

${ }^{27}$ Ibid., p. 102.

${ }^{28}$ D. LaCapra, Representing the Holocaust, p. 46.

${ }^{29}$ Comentando el caso de una sobreviviente de Auschwitz que en su relato se refirió a "las cuatro chimeneas" del campo de concentración, LaCapra afirma que su testimonio no queda invalidado por ninguna reconstrucción empírica, puesto que lo que la mujer testifica es su experiencia personal. Cfr. Writing History, Writing Trauma, pp. 86-89. 
hace impensable la noción de que un testigo pudiese existir [...]. Se podría decir que no ha habido, históricamente hablando, testigo alguno del Holocausto." 30 Sin embargo, como resultado de la relación transferencial que el historiador mantiene con su objeto de estudio, los procesos activos de la misma se repiten en el relato historiográfico. Es decir, el rasgo de la implicación del historiador se manifiesta en la tendencia a repetir, de un modo u otro, los aspectos traumáticos de los procesos estudiados en el resultado de su investigación. Reconocer un aspecto transferencial en la comprensión histórica de acontecimientos límites supone aceptar una tendencia a la identificación con los participantes de los mismos. De este modo, la repetición se encuentra presente en el relato del historiador en la medida en que éste está implicado afectivamente en los problemas que estudia.

La elaboración —que en su traducción inglesa (working through) conserva la noción de "trabajo" que Freud le diera en la acepción alemana (Durcharbeitung) — es una práctica articuladora que, dentro de la relación de transferencia, intenta distinguir el pasado del presente. Para Freud, la elaboración designa el componente dinámico de una actividad cognitiva que conduce al reconocimiento cuando está enderezada contra las resistencias. Es decir, la elaboración trata de contrarrestar la fuerza que empuja a repetir compulsivamente, y de transformar la experiencia repetida en un recuerdo, restituyendo la distancia crítica con el presente: involucra el intento de adquirir cierta perspectiva sobre la experiencia sin, por eso mismo, negarla. Aceptado el aspecto transferencial de la comprensión histórica de eventos extremos, la elaboración se transforma, entonces, en un momento necesario de la misma, cuyo objetivo es restituir la distancia crítica con dichos acontecimientos a través de la escritura histórica, conciliando, así, a los grupos con su pasado. Esta dimensión de la comprensión histórica posee consecuencias ético-políticas en la medida en que permitiría recuperar las dimensiones temporales que son condición de posibilidad para la acción responsable: ni una fidelidad ciega al pasado, ni un olvido del mismo. Sin embargo, aquellos que adoptan esta perspectiva teórica en la historiografía reconocen que, con respecto a un fenómeno de las características increíbles del Holocausto, "puede ser imposible, aun para aquellos nacidos más tarde, trascender el evento completamente y ponerlo en el pasado, simplemente como lo pasado". ${ }^{31}$ La naturaleza traumática del acontecimiento excede cualquier cierre de tipo narrativo e impide, por lo mismo, escribir su historia.

La cuestión de la interpretación de los fenómenos socioculturales en términos psicoanalíticos conlleva, a mi entender, la negación de la posibilidad de la historia del presente, al menos en aquellas sociedades con pasados

${ }^{30}$ D. Laub, "Truth and Testimony: The Process and the Struggle", p. 66.

${ }^{31}$ D. LaCapra, Writing History, Writing Trauma, p. 152. 
recientes traumáticos. La temporalidad del trauma es incompatible con la temporalidad histórica, tanto si el fenómeno de la repetición es entendido como el retorno de lo reprimido o el retorno de lo literal. La identificación de la comprensión histórica con la situación analítica de la transferencia tiene como consecuencia la absorción de la repetición traumática en el trabajo del historiador: la circularidad propia de la temporalidad repetitiva no puede ser trascendida. Tanto el terapeuta como el historiador son "contagiados" por la tendencia de la víctima a contaminar a otros. Ni la cura, en el caso del psicoanálisis, ni el relato historiográfico, en el caso de la historia, logran cerrar nunca por completo la brecha entre la memoria traumática y la memoria narrativa.

Aún después de un tiempo considerable —señala van der Kolk—y aún después de adquirir una narrativa personal de la experiencia traumática, la mayoría de nuestros sujetos reportan que dichas experiencias continuaron retornando como percepciones sensoriales y como estados afectivos.

[...] La persistencia de las sensaciones intrusivas relacionadas con el trauma, aún después de la construcción de la narrativa, contradice la noción de que aprender a poner la experiencia traumática en palabras ayudará a abolir la ocurrencia de la repetición. ${ }^{32}$

La pretensión de la historia de corte psicoanalítico de conciliar a los grupos, a través del relato historiográfico, con las heridas y cicatrices del pasado es invalidada desde el interior mismo del psicoanálisis.

La noción de memoria traumática como la imposibilidad de organizar retrospectivamente los acontecimientos en una narración con sentido obstruye la distinción entre pasado y presente. Dicha distinción constituye la condición de posibilidad de la temporalidad histórica, fundamento de la historia como disciplina profesional. En un trabajo anterior señalé tres articulaciones posibles del presente con el pasado, utilizando para este último la categoría metahistórica de espacio de experiencia (Koselleck). Allí mencioné que "lo específico de un presente caracterizado por lo que denominamos conciencia histórica es la organización retroactiva del pasado por medio de la crítica de lo efectivamente transmitido por la tradición". ${ }^{33}$ En un presente histórico convive un sentido de la continuidad con el pasado, pero, a su vez, un sentido de alteridad con el mismo: el presente se vive como algo diferente aun cuando se lo piense como resultado del pasado: "esta apreciación de la otredad es consecuencia de la instancia crítica que el presente ejerce sobre los contenidos de sentido transmitidos por el pasado".

${ }^{32}$ B. van der Kolk et al., Traumatic Stress: The Effects of Overwhelming Experience on Mind, Body, and Society, p. 46.

33 M.I. Mudrovcic, "El valor heurístico de un análisis formal del concepto de tradición". 
La temporalidad repetitiva del trauma puede ser equiparada con la noción de reiteración que el presente hace del pasado en las sociedades tradicionales. La palabra reiteración posee el mismo alcance que le dio Mircea Eliade para señalar que el acontecimiento mítico no se conmemora, sino que se reitera en el sentido de hacerse contemporáneo con el presente. Una sociedad inmersa en la tradición es aquella para la que no hay diferencias cualitativas entre pasado, presente y futuro. Su presente es el ámbito de reiteración del pasado a través de la repetición analógica de actos que, se espera, se reproduzcan en el futuro. ${ }^{34}$ En consecuencia, tanto la "temporalidad repetitiva" de un grupo inmerso en el trauma como la "temporalidad reiterativa" de un grupo inmerso en la tradición ocluyen la posibilidad de la historia, para la que es fundamental la distancia crítica con el pasado. Prueba de ello lo constituye la breve síntesis de la historia de la historiografía alemana acerca del Holocausto dada por Lorenz en el I Congreso Internacional de Filosofía de la Historia, realizado en octubre del año pasado en Buenos Aires. A la pregunta "¿Cómo fue posible ESTO —el Holocausto?", Lorenz afirma que los historiadores alemanes han respondido de modo cambiante al problema del "trauma nazi". El periodo comprendido entre 1945 y 1965 se caracteriza, según Lorenz, como una época de "represión casi completa" de la catástrofe judía. Historiadores como Ritter, Schieder, Conze y Erdmann, "nacidos entre 1900 y 1910 y así completamente maduros y activos durante el régimen nazi", ignoran ("rechazan", "reprimen" —en palabras de Lorenz) la catástrofe judía para ocuparse de la catástrofe alemana; es decir, no escriben la historia del Holocausto. En el segundo periodo, que comprende desde 1965 a 1990, escriben los "hijos de los perpetradores", es decir, los historiadores nacidos entre 1930 y 1940, los "Mommsens, Broszat, Nipperdey, Winkler, Wehler, etc." Para Lorenz, este periodo se caracteriza por el "retorno de lo reprimido, esto es: el Holocausto", pues aunque estos historiadores pusieron en su agenda al Tercer Reich, "evitaron investigar sobre la ejecución real del Holocausto". Finalmente, en el tercer periodo que comienza, para Lorenz, en 1989, los jóvenes historiadores alemanes "están investigando el papel de sus ancestros como perpetradores del Holocausto", es decir, la historiografía alemana "ha entrado en la fase de elaboración del Holocausto y de realmente 'resignarse' al pasado nazi". ${ }^{35}$ Lorenz caracteriza sucesivamente los tres periodos como: represión completa, retorno de lo reprimido y elaboración. Los dos primeros se caracterizan por una ausencia de la escritura de la historia del Holocausto. Para decirlo en otros términos: la memoria traumática del espacio de experiencia de los grupos implicados impide el ajuste retroactivo

${ }^{34}$ Cfr. ibid.

${ }^{35}$ C. Lorenz, “¿Historia como trauma? Algunas reflexiones acerca de los debates alemanes sobre la historia nazi". 
del pasado; la temporalidad repetitiva del trauma obstaculiza escribir su historia. Donde hay trauma no hay historia. Psicoanálisis e historia se enfrentan como dos estrategias diferentes de distribuir el tiempo de la memoria. Organizan de modo distinto la relación entre pasado y presente: la historia instaura una ruptura necesaria allí donde el psicoanálisis postula una contigüidad.

La teoría del trauma aplicada a las reconstrucciones historiográficas del pasado reciente constituye una contribución inesperada a lo que Hacking ha denominado la "memoro-política" de nuestros tiempos: ${ }^{36}$ nadie quiere ser una víctima, pero aspirar a la condición de víctima conlleva indudables beneficios. En efecto, el trauma es una manera de "construir" un determinado tipo de personas, una forma en que los individuos pueden concebirse a sí mismos y a partir de la cual adquirir derechos para cierto tipo de compensaciones. Todorov lo enuncia muy crudamente citando a Alain Finkielkraut: "el linaje me convertía en el concesionario del genocidio, en su testigo y casi en su víctima", y más adelante agrega: "si se consigue establecer de manera convincente que un grupo fue víctima de la injusticia en el pasado, esto le abre en el presente una línea de crédito inagotable". ${ }^{37}$ Sin embargo, y si se es consecuente, cuando el modelo es aplicado a las víctimas del Holocausto, a los veteranos de Vietnam o a los sobrevivientes de Hiroshima, implica que todos los participantes en dichos acontecimientos - ya sean las víctimas que sufren de repetitivos flashbacks o los perpetradores que ahora sienten culpa por lo que alguna vez hicieron- están sujetos a las mismas consecuencias. La expansión que permite la categorización de los fenómenos del pasado reciente como traumáticos conlleva la tendencia a colapsar las distinciones entre víctimas y perpetradores, o simplemente entre las víctimas y los que no lo son. El relato que nos ofrece Lorenz de la historiografía alemana es un ejemplo de ello. La razón de por qué la primera generación de historiadores no escribió acerca del Holocausto la encuentra Lorenz en la "represión casi completa" del "trauma del periodo nazi". Los historiadores, nos dice, "como la mayoría de los alemanes de la época, no eran capaces de aceptar la culpa por el Holocausto, no eran capaces de interpretar la historia nazi como suya". Ahora bien, si no eran "capaces" por estar directamente implicados en el trauma nazi, tampoco podemos imputarles responsabilidad por haber silenciado la historia de la catástrofe judía. La represión, por su misma naturaleza inconsciente, impide, como hemos visto, cualquier tipo de distancia que permita una aproximación cognitiva a la experiencia traumática, por lo que neutraliza todo tipo de demanda de responsabilidad social, ética y política.

\footnotetext{
${ }^{36}$ I. Hacking, "Memory Sciences, Memory Politics".

${ }^{37}$ T. Todorov, op.cit., p. 54.
} 
Escribir la historia es hacerse cargo del pasado. Justificar su ausencia invocando una "memoria reprimida" es desresponsabilizar al historiador del alcance de su tarea. La apelación indiscriminada al trauma exime tanto de imputación moral como de imputación cognitiva.

La fascinación que el modelo psicoanalítico del trauma ha ejercido sobre la historiografía del pasado reciente contribuyó a oscurecer y colapsar importantes diferencias entre ambas disciplinas. Aun cuando en el nivel de la ontología se reconozca una temporalidad repetitiva como constitutiva de los procesos históricos, la misma no debe ser extrapolada al conocimiento histórico, tal como sucede si se interpreta este último como relación de transferencia. El conocimiento histórico, en cuanto ajuste retroactivo del pasado, presupone la distinción entre éste y el presente: la temporalidad reiterativa de las sociedades tradicionales no impide conocerlas históricamente.

En otro nivel no menos importante, debemos señalar que concebir la tarea de la historia como la reconciliación de los pueblos con sus pasados traumáticos soslaya la función cognitiva primaria de la disciplina. Llegamos aquí a un punto en que se debe resaltar la falta de paralelismo entre el psicoanálisis y la historia con respecto al papel que desempeña el conocimiento en ambas. Freud es muy claro al respecto: las resistencias no se sortean comunicando al paciente el conocimiento de los resultados del trabajo interpretativo del terapeuta. ${ }^{38}$ Por el contrario, la comunicación de los resultados obtenidos a partir de la investigación documental constituye el objetivo de la operación historiográfica. Que dichos resultados contribuyan, a través del debate público, a conciliar a los grupos con su pasado es función derivada y no primaria de la historia. Pensar lo contrario es transformar al historiador en terapeuta social.

\section{BIBLIOGRAFÍA}

Adorno, T., Prisms, The MIT Press, Cambridge, Mass., 1981.

Bar-On, D., The Indescribable and Undiscussible. Reconstructing Human Discourse after Trauma, Central European University Press, Budapest/ Nueva York, 1999.

Burke, P., History and Social Theory, Cornell University Press, Nueva York, 1992.

Caruth, C., Unclaimed Experience: Trauma, Narrative and History, The Johns Hopkins University Press, Baltimore, 1996.

Certau, M. de, Historia y psicoanálisis, Universidad Iberoamericana, México, 1995.

Freud, S., "Contribution à l'histoire du mouvement psychanalytique", Cinq leçons sur la psychanalyse, Payot, París, 1966.

—_, "Más allá del principio del placer", Obras completas, vol. XVIII, Amorrortu, Buenos Aires, 1991, pp. 1-62.

${ }^{38}$ Freud, "Recordar, repetir y elaborar", p. 149. 
Freud, S., "Recordar, repetir y elaborar", Obras completas, vol. XII, Amorrortu, Buenos Aires, 1991, pp. 145-157.

Gilmore, L., The Limits of Autobiography: Trauma and Testimony, Cornell University Press, Ithaca, 2001.

Hacking, I., "Memory Sciences, Memory Politics", en Paul Antze (comp.), Tense Past: Cultural Essays in Trauma and Memory, Routledge, Nueva York, 1996, pp. 67-87.

Hilberg, R., "I Was Not There", en Berel Lang (comp.), Writing and the Holocaust, Holmes and Meier, Nueva York, 1988.

Janet, P., Psychological Healing. A Historical and Clinical Study, Macmillan, Nueva York, 1976 (1919), p. 661.

LaCapra, D., Representing the Holocaust. History, Theory, Trauma, Cornell University Press, Nueva York, 1994.

—, Writing History, Writing Trauma, The Johns Hopkins University Press, Baltimore, 2001.

Langer, W., "The New Assignment", American Historical Review, no. 63, 1958, pp. 283-304.

Langmuir, G., History, Religion, and Antisemitism, University of California Press, Berkeley, 1990.

Laub, D., "Truth and Testimony: The Process and the Struggle", en C. Caruth, Trauma: Explorations in Memory, The Johns Hopkins University Press, Baltimore, 1995, pp. 66-68.

Leys, R., Trauma. A Genealogy, The University of Chicago Press, Chicago, 2000.

Lorenz, C., "¿Historia como trauma? Algunas reflexiones acerca de los debates alemanes sobre la historia nazi", ponencia presentada en el I Congreso Internacional de Filosofía de la Historia, Universidad de Buenos Aires, 2000.

Mudrovcic, M.I., "Algunas consideraciones epistemológicas para una 'Historia del presente", Hispania Nova, Revista de Historia Contemporánea, no. 1, marzo de 2000, http://hispanianova.rediris.es/general/articulo/013/art013.htm.

__ , "El valor heurístico de un análisis formal del concepto de tradición", Prismas. Revista de Historia Intelectual (Universidad Nacional de Quilmes, Buenos Aires), no. 5, 2001, pp. 329-336.

Neal, A., National Trauma and Collective Memory: Major Events in the American Century, M.E. Sharpe, Armonk, N.Y., 1988.

Popov, N., The Road to War in Serbia. Trauma and Catharsis, Central European University Press, Budapest/ Nueva York, 1999.

Rothberg, M., Traumatic Realism. The Demands of Holocaust Representation, The University of Minnesota Press, Minneápolis, 2000.

Sherwood, M., The Logic of Explanation in Psychoanalysis, Academic Press, Nueva York, 1969.

Spence, D., Historical Truth and Narrative Truth: Meaning and Interpretation in Psychoanalysis, W.W. Norton, Nueva York, 1982.

Todorov, T., Los abusos de la memoria, trad. Miguel Salazar, Paidós Barcelona, 2000. Van der Kolk, B., "The Body Keeps the Score: Memory and the Evolving Psychobiology of Post Traumatic Stress", Harvard Review of Psychiatry, vol. 1, no. 5, 1994, pp. 253-265 [existe una versión en internet: http//www.traumapages.com/vanderk4.htm]. 
Van der Kolk, B., A. McFarlane y L. Weisath, Traumatic Stress: The Effects of Overwhelming Experience on Mind, Body, and Society, Guilford Press, Nueva York, 1996.

Wartes, E., Memory Quest: Trauma and the Search for Personal History, 1997.

Wiesel, E., Against Silence: The Voice and Vision of Elie Wiesel, ed. Irving Abrahamson, Holocaust Library, Nueva York, 1985.

Recibido el 19 de marzo de 2002; aceptado el 30 de abril de 2002 